\title{
Vertebral fractures and bone mineral density in idiopathic, secondary and corticosteroid associated osteoporosis in men
}

\author{
S F Evans, M W J Davie
}

\begin{abstract}
Objective-To investigate bone mineral density (BMD) in men with symptomatic osteoporosis and compare BMD in patients with idiopathic, secondary and corticosteroid associated osteoporosis.

Methods-Age, number of vertebral fractures at presentation and BMD were investigated in men presenting to a bone metabolism clinic with idiopathic $(n=105$; group 1), secondary ( $n=67$; group 2 ) and corticosteroid osteoporosis $(n=48$; group 3). BMD was measured in 176 healthy men (controls). Osteoporosis was diagnosed if there was $\geqslant 20 \%$ vertebral deformity.

Results-Age at peak BMD in controls was 20-29 years at spine (LS-BMD) and femoral neck (FN-BMD). LS-BMD did not change with age but FN-BMD decreased in controls and groups 1 and 2 . Mean (SD) age was similar in groups 1 $(62.8(11.5)$ years, $2(60.2(11.0))$ years and $3(62.7(10.4)$ years with $45 \%, 51 \%$ and $40 \%$ of patients respectively presenting before 60 years. Back pain, present for up to 12 months, was the commonest cause of referral. Vertebral fractures at presentation averaged mean (SD) 2.51 (1.9) in group $1,2.76(2.2)$ in group 2 and $2.48(1.8)$ in group 3. $L S-B M D Z$ scores and $T$ scores were more negative in group 1 patients with $\leqslant 3$ vertebral fractures compared with FN-BMD suggesting a greater trabecular bone deficit. LS-BMD Z score in group 1 is -1.71 , lower than in population studies. LS T score associated with fracture was about -2.4 in all groups. T8, T12 and L1 were the most frequent levels for fracture.
\end{abstract}

Conclusions-Men with symptomatic osteoporosis present in middle age, have low BMD with similar $T$ scores irrespective of aetiology and sustain $\geqslant 1$ fracture.

(Ann Rheum Dis 2000;59:269-275)

Vertebral osteoporosis in men has received increased attention since the EVOS study highlighted higher prevalences than previously thought, even, in some countries, exceeding the prevalence in women. ${ }^{1}$ In the clinical setting vertebral osteoporosis in men may be overlooked, and a recent review devoted little comment to the clinical presentation emphasising instead the pathological associations. ${ }^{2}$ Population studies in men suggest that there is a poor relation between radiological vertebral deformity and back pain, ${ }^{1}$ or complaints, ${ }^{3}$ although studies of clinical osteoporosis do indicate that back pain is an important association. ${ }^{4}$ These observations raise the question of whether subjects found to have vertebral deformity on population screening differ from patients referred with clinical osteoporosis.

There may also be a difference between the mean age of patients with clinical vertebral osteoporosis and subjects in population studies. In the EVOS study the prevalence of male vertebral deformity remained steady between the ages of $55-75$ years. ${ }^{1}$ Male osteoporosis has often been considered a disease of the elderly. Francis et a $\bar{l}$ found that by the 60 th year, $3 \%$ of men had sustained a fracture at the forearm, femoral neck or vertebral body and that this increased to $8 \%$ by 80 years. However, the mean (SD) age at presentation of clinical vertebral fracture may be lower, being reported as 46.1 (13.0) in patients with vertebral fracture in primary osteoporosis, ${ }^{6} 54.7$ (14.0) in secondary osteoporosis, ${ }^{6} 55.4$ in a series including both vertebral fracture and low bone density $^{7}$ and $57.8(10.4)$ in a series of idiopathic osteoporosis. ${ }^{8}$ The early age of presentation may relate not only to ease of referral to a specialist centre but also to the aetiology of vertebral fracture. Few investigations have concentrated on determining whether idiopathic, secondary or corticosteroid related osteoporosis present at different ages. Uncertainties also relate to the numbers of vertebral fractures at presentation: multiple fractures might denote delay in the diagnosis. Equally it is unclear whether vertebral fracture number is related to bone mineral density (BMD) or whether vertebral fractures in corticosteroid induced osteoporosis in men occur at higher than expected BMD values. ${ }^{9}$ Therefore we have also sought to identify some characteristics of osteoporosis in patients referred for treatment and to compare these with population studies of vertebral deformity. We have also compared the value of BMD that is associated with different aetiologies of clinical osteoporosis with values reported in population vertebral deformity studies.

\section{Methods}

PATIENTS

Two hundred and twenty male patients were included if referred for specialist opinion because of symptoms, and if radiographs showed the presence of one or more fractures between T4 and L5. In four cases fractures in the spine were identified during the course of a work related medical examination. Fractures at
Accepted for publication 28 October 1999 
Table 1 Characteristics and modes of presentation of subjects with osteoporosis

\begin{tabular}{|c|c|c|c|c|c|}
\hline & & $\begin{array}{l}\text { Group } 1 \\
\text { (idiopathic) }\end{array}$ & $\begin{array}{l}\text { Group } 2 \\
\text { (secondary) }\end{array}$ & $\begin{array}{l}\text { Group } 3 \\
\text { (corticosteroid) }\end{array}$ & $\begin{array}{l}\text { Controls } \\
\text { (matched for age } \\
\text { range) }\end{array}$ \\
\hline Age $(y)$ mean $(S D)$ & & $62.8(11.5)$ & $60.2(11.0)$ & $62.7(10.4)$ & $57.0(10.7)$ \\
\hline Range (y) & & $38.3-89.1$ & $38.6-92.1$ & $39.9-81.1$ & $38.2-90.8$ \\
\hline Number & & 105 & 67 & 48 & 119 \\
\hline Previous fracture (\%) & & 45 & 56 & 51 & 40 \\
\hline Family history of fracture (\%) & & 15 & 19 & 10 & NA \\
\hline Previous back pain (\%) & & 22 & 27 & 17 & NA \\
\hline Current back pain (\%) & & 88 & 84 & 88 & 28 \\
\hline Previous radiograph of spine (\%) & & 90 & 98 & 85 & NA \\
\hline \multicolumn{6}{|l|}{ Additional reasons cited as a cause for referral } \\
\hline Radiography because on corticosteroids & No & & & 5 & \\
\hline Non-back pain & No & 8 & 4 & 3 & \\
\hline Height loss & No & 4 & 1 & 1 & \\
\hline Non-vertebral fracture & No & 1 & 6 & 2 & \\
\hline Radiograph after fall & No & 1 & 3 & & \\
\hline Radiograph after fit & No & & 1 & & \\
\hline Medical & No & 3 & 1 & & \\
\hline
\end{tabular}

$\mathrm{NA}=$ not available

non-spinal sites were not taken into account in the present analysis. Thus all subjects were symptomatic and not identified by screening. Most patients had complained of back pain to their primary care physician and $85-98 \%$ (according to group, see below) had undergone radiography before referral. Table 1 gives the causes of referral. No patient in any of the three osteoporotic groups had received treatment for osteoporosis up to the time of their first clinic appointment. Back pain after a fall from more than standing height, or the presence of a neoplasm, including myeloma, excluded from any of the three groups.

Three separate groups of osteoporotic men were identified (table 1). Group 1 included 105 men with idiopathic osteoporosis. In this group there was no apparent cause for their osteoporosis. In group 2, 67 men were identified with a secondary cause of osteoporosis. Twenty four had alcohol (>28 U/week) as an aetiological factor, 10 exhibited low serum testosterone ( $<8 \mathrm{nmol} / \mathrm{l})$, nine had undergone partial gastrectomy, and nine suffered from epilepsy. Each of the following occurred in three patients: hiatus hernia, vagotomy and pyloroplasty, colostomy. One patient each had: weight loss, congenital cataract, thyrotoxicosis, myelitis, schizophrenia, osteogenesis imperfecta. In group 3, 48 men with osteoporosis associated with corticosteroid treatment were investigated. The reasons for taking corticosteroids were: obstructive airways disease or fibrosing alveolitis $(\mathrm{n}=31)$, inflammatory bowel disease $(n=6)$, polymyalgia, temporal arteritis or rheumatoid arthritis $(n=6)$, skin diseases $(n=3)$, red cell aplasia $(n=1)$ and pulmonary fibrosis $(n=1)$. Lifetime corticosteroid dose was assessed (dose/day $\times$ number of days taken) using information from the clinical notes. The corticosteroid was invariably prednisolone: daily dose was between $2-80 \mathrm{mg} /$ day (mean (SD) 14.9 (15.6) (median=10) $\mathrm{mg} /$ day) and had been taken for a median of 8 years $(0.3-50)$, resulting in a calculated cumulative dose of between 3.7-127.8 g (39.7 (35.9) (median=26.7) g).

HEALTHY SUBJECTS

To compare patients having osteoporosis with normal subjects, we examined data (table 2) from 176 healthy male volunteers (controls), taking part in a concurrent, though independent, study of bone density and turnover in men to establish values for normal subjects. These subjects were aged 20-91 years and, from their data, values for $\mathrm{T}$ scores and $\mathrm{Z}$ scores in 10 year groupings up to 79 years and over 80 years were calculated. Numbers in groups over 70 years were smaller than for younger groups. All subjects are included in table 2 , but in table 4 only healthy subjects in the same age range as patients with osteoporosis are included (see legend). Healthy men were evaluated by a questionnaire seeking out risk factors for osteoporosis, assessment of general health, previous fracture and present back pain. Fractures that excluded subjects from the healthy group were known vertebral fractures and hip fractures.

Ethical approval for the study of the controls was granted from the Shropshire Research Ethics Committee. Permission to obtain radiographs of the spine in controls was not obtained.

\section{RADIOGRAPHS}

Fractures were defined as $\geqslant 20 \%$ wedge deformity ((1-(anterior height/posterior height $) \times 100$ ) or central deformity (crush) $((1-$ (mid-height/posterior height $)) \times 100)$ identified at the time of first attendance. All patients had radiographs taken at the clinic. Measurements were made from these radiographs. Obvious deformities were measured by one author (MWJD). In cases of less obvious deformity the vertebrae were measured by both authors and only included if both agreed with the criteria.

\section{BMD MEASUREMENTS}

BMD was measured at the lumbar spine (L2-4) (LS-BMD) and at the left femoral neck (FN-BMD) using DXA (Hologic QDR1000 or $1000 / \mathrm{W}$, Hologic Corp, Waltham, MA, USA). In the patient groups the measurements were made at the first visit, before any treatment had been started. All the original data for patients and controls were analysed using the same software edition to avoid discrepancies arising from software changes. BMD of the phantom supplied with the Hologic QDR densitometer was measured daily during the working week. No measurements of the patients were undertaken unless 
Table 2 BMD of normal men

\begin{tabular}{lllll}
\hline & Number & Age & $L S-B M D$ & $F N-B M D$ \\
\hline $20-29$ & 28 & $25.1(2.9)$ & $1.08(0.12)$ & $0.96(0.13)$ \\
$30-39$ & 30 & $34.7(2.7)$ & $1.06(0.11)$ & $0.90(0.13)$ \\
$40-49$ & 27 & $44.9(3.2)$ & $1.04(0.16)$ & $0.85(0.11)$ \\
$50-59$ & 42 & $54.5(3.0)$ & $1.09(0.15)$ & $0.88(0.13)$ \\
$60-69$ & 38 & $64.5(3.0)$ & $1.00(0.15)$ & $0.79(0.13)$ \\
$70-79$ & 6 & $75.8(3.2)$ & $1.09(0.20)$ & $0.80(0.07)$ \\
$>80$ & 5 & $83.6(4.1)$ & $1.02(0.19)$ & $0.74(0.04)$
\end{tabular}

Data shown as mean (SD).

Table 3 Fracture prevalence at presentation according to duration of back pain

\begin{tabular}{llll}
\hline $\begin{array}{l}\text { Duration of } \\
\text { pain (months) }\end{array}$ & $\begin{array}{l}\text { Group 1 } \\
\text { (idiopathic) }\end{array}$ & $\begin{array}{l}\text { Group 2 } \\
\text { (secondary) }\end{array}$ & $\begin{array}{l}\text { Group 3 } \\
\text { (corticosteroid) }\end{array}$ \\
\hline $0-6$ & $2.37(1.98)$ & $1.64(0.92)$ & $3.15(2.41)$ \\
$6-12$ & $2.67(1.92)$ & $3.60(1.96)$ & $1.50(0.84)$ \\
$12-24$ & $1.86(0.90)$ & $1.67(1.12)$ & $2.29(1.11)$ \\
$24-60$ & $1.20(0.45)$ & $3.50(3.39)$ & $3.00(2.83)$ \\
$>60$ & $3.50(2.02)$ & $3.40(3.29)$ & $2.25(1.50)$ \\
\hline
\end{tabular}

Data shown as mean (SD).

the equipment was stable and working within specification. The coefficient of variation (CV) of the lumbar spine measurement was $1.45 \%$ and of the femoral neck was $2.07 \% .{ }^{10}$ Variation between the two densitometers was $<0.5 \%$. Standing height was measured in all subjects using a Harpenden Stadiometer (Holtain Ltd, Crymych, Dyfed, UK).

STATISTICAL METHODS

Mean (SD) results are given together with the median if appropriate. Correlations were assessed by the Spearman ranking method and comparisons between groups were made using the Kruskall-Wallis test with subsequent testing by Mann-Whitney U test (Excel, Microsoft Corp, Seattle, Washington). The $\chi^{2}$ test was used to investigate trends, ${ }^{11}$ and to compare proportions.
To calculate $\mathrm{Z}$ scores, the mean of the appropriate age group in the control men was taken. $\mathrm{Z}$ score $(\mathrm{BMD})=\left(\mathrm{BMD}_{\mathrm{p}}-\mathrm{BMD}_{\mathrm{c}}\right) /$ $\mathrm{BMD}_{\mathrm{d}},\left(\mathrm{BMD}_{\mathrm{p}}=\mathrm{BMD}\right.$ measurement of patient; $\mathrm{BMD}_{\mathrm{c}}=$ mean $\mathrm{BMD}$ of the same age group from the control group of men; $\mathrm{BMD}_{\mathrm{d}}=$ standard deviation in BMD of the same age group from the control group of men). To calculate $\mathrm{T}$ scores, peak BMD at the lumbar spine and femoral neck of the control men was used. For both the lumbar spine and the femoral neck this was 20-29 years. $T$ scores were calculated in the same way as $Z$ scores (except that $\mathrm{BMD}_{\mathrm{c}}=$ mean $\mathrm{BMD}$ of peak $\mathrm{BMD}$ in controls and $\mathrm{BMD}_{\mathrm{d}}=$ standard deviation at peak BMD).

\section{Results}

The average age of men presenting with idiopathic osteoporosis (group 1) was similar to those having secondary osteoporosis (group 2) (table 1), and to the patients whose osteoporosis was associated with corticosteroid ingestion (group 3). Of those in group 1, 45\% were aged less than 60 years when they presented with an osteoporotic fracture, compared with $51 \%$ in group 2 and $40 \%$ in group 3. Some $91.5 \%$ of patients had had a radiograph of the spine before referral. Patients were also compared with a group of controls matched for age range, but with a mean age slightly lower. Previous fracture (non-vertebral site) occurred in about half of the osteoporotic groups, though it was also frequent in the control subjects. Only five patients in the osteoporotic groups had had a previous hip fracture. The known family history of fracture was also similar across all groups. Back pain in the past was also uncommon. Most were experiencing current back pain and this symptom was

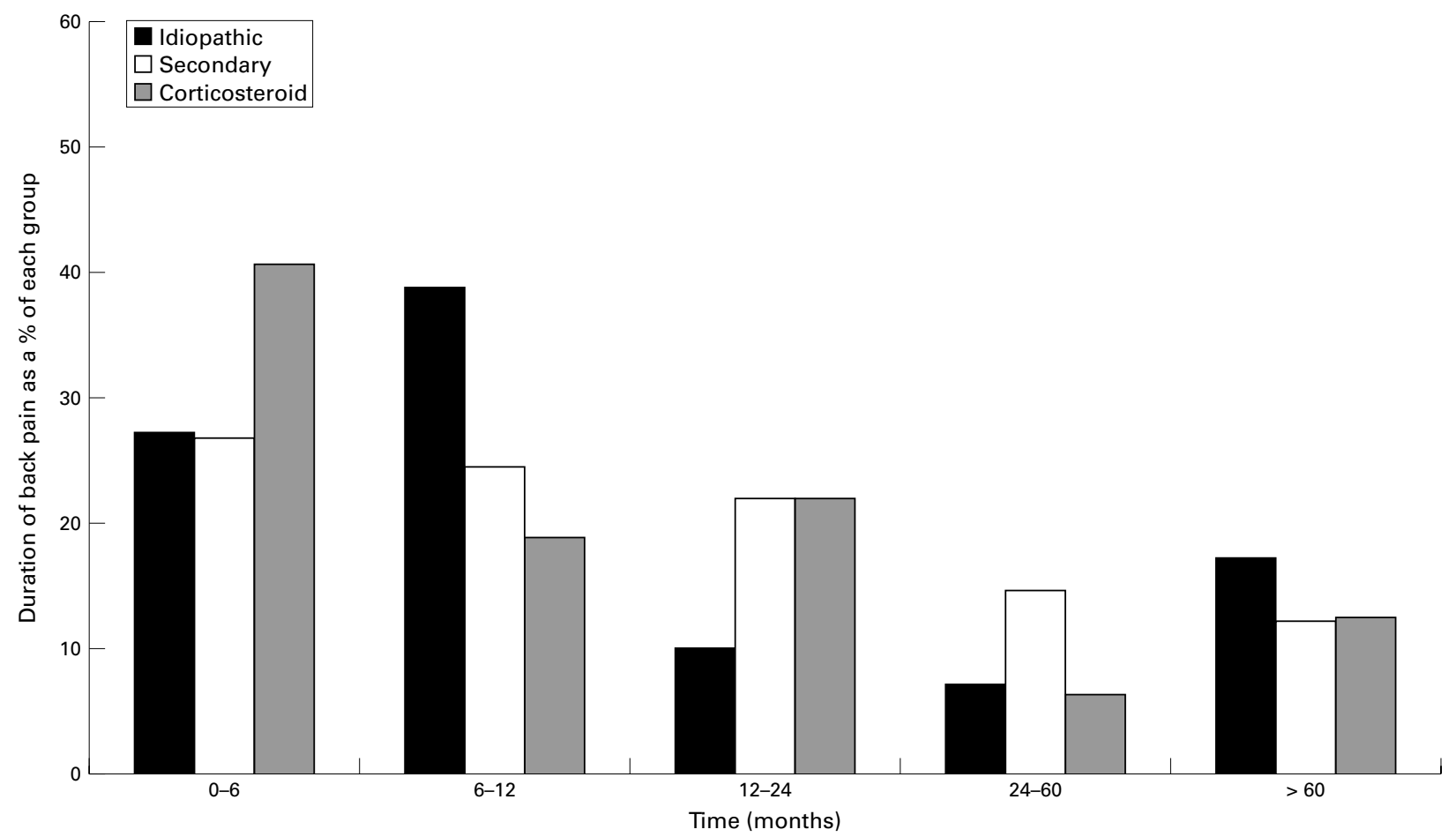

Figure 1 Frequency histogram of duration of back pain (as \% of each group) in the three groups of osteoporotic men. 
Table 4 Bone mineral density in patients with osteoporosis paired for age with control subjects

\begin{tabular}{llll}
\hline Group 1 & Idiopathic (92) & Controls (92) & $p$ \\
\hline Age & $60.7(10.3)$ & $60.1(10.0)$ & NS \\
Height & $1.70(0.08)$ & $1.74(0.06)$ & $<0.001$ \\
Weight & $75.61(12.34)$ & $79.21(11.01)$ & NS \\
LS BMD & $0.78(0.13)$ & $1.05(0.16)$ & $<0.001$ \\
LS z score & $-1.71(0.92)$ & & \\
LS T score & $-2.48(1.09)$ & & \\
FN BMD & $0.68(0.09)$ & $0.84(0.13)$ & $<0.001$ \\
FN z score & $-1.33(1.10)$ & & \\
FN T score & $-2.13(0.73)$ & & \\
& & & \\
Group 2 & Secondary (67) & Controls (67) & p \\
Age & $60.2(11.0)$ & $59.9(10.8)$ & NS \\
Height & $1.69(0.07)$ & $1.73(0.06)$ & $<0.001$ \\
Weight & $71.22(13.61)$ & $78.33(11.11)$ & $<0.001$ \\
LS BMD & $0.80(0.13)$ & $1.06(0.17)$ & $<0.001$ \\
LS z score & $-1.6(0.90)$ & & \\
LS T score & $-2.37(1.09)$ & & \\
FN BMD & $0.66(0.13)$ & $0.84(0.12)$ & $<0.001$ \\
FN z score & $-1.57(1.36)$ & & \\
FN T score & $-2.27(0.97)$ & & \\
& & & \\
Group 3 & Corticosteroid (48) & Controls (48) & $\mathrm{p}$ \\
Age & $62.7(10.4)$ & $62.4(10.3)$ & NS \\
Height & $1.68(0.07)$ & $1.73(0.06)$ & $<0.001$ \\
Weight & $70.47(14.15)$ & $79.29(12.75)$ & $<0.01$ \\
LS BMD & $0.78(0.14)$ & $1.04(0.16)$ & $<0.001$ \\
LS z score & $-1.70(0.94)$ & & \\
LS T score & $-2.52(1.16)$ & & \\
FN BMD & $0.65(0.12)$ & $0.84(0.14)$ & $<0.001$ \\
FN z score & $-1.66(1.39)$ & & \\
FN T score & $-2.42(1.39)$ & & \\
\hline Dat shown as & & \\
\hline
\end{tabular}

Data shown as mean (SD).

significantly more frequent in each of the osteoporotic groups than in the control men $\left(\chi^{2}\right.$ $<0.001$ for controls versus any of the osteoporotic groups). The duration of back pain before clinic attendance was ascertained in patients whose complaint was back pain (fig 1). Some $65.7 \%$ of idiopathic patients, $51.2 \%$ of secondary and $59.4 \%$ of corticosteroid patients all reported pain only over the previous 12 months. However, a significant minority of patients had been experiencing pain for two years or more. There was no association between number of fractures and duration of the pain in any group (table 3). Causes of referral other than back pain were uncommon.

The average number of vertebral fractures at presentation in group 1 was 2.51 (1.9); in group 2 it was $2.76(2.2)$ and in group 3 it was 2.48 (1.8) (differences between 3 groups = NS). Vertebral fracture number increased with increasing age in group $1(\mathrm{p}<0.01)$, but there was no similar tendency in groups 2 or 3 . Vertebral fracture number showed no relation with LS-BMD, FN-BMD, or with lumbar spine or femoral neck $\mathrm{T}$ and $\mathrm{Z}$ scores (see methods for derivation and below for values used for normal range) in any group. $\mathrm{T}$ score in the lumbar spine in each of the three osteoporotic groups was analysed by age. $\mathrm{T}$ score did not show any trend with age in any group.

Body height decreased significantly with increasing fracture number in group 1 $(\mathrm{p}<0.05)$ and group $2(\mathrm{p}<0.01)$ but not in group 3. Body weight decreased significantly as fracture number increased in group $1(\mathrm{p}<0.05)$ only.

Cross sectional BMD in control subjects at the lumbar spine showed a slight, but not significant fall with age. Peak BMD occurred at 50-59 years $\left(1.09(0.15) \mathrm{g} / \mathrm{cm}^{2}\right)$ (table 2$)$, but was almost identical to the BMD at 20-29 years $\left(1.08(0.12) \mathrm{g} / \mathrm{cm}^{2}\right)$ and this latter value was used to calculate the $\mathrm{T}$ scores. At the femoral neck, BMD did exhibit a significant decline with age $(p<0.01)$, but the slope was not steep, being only $0.0034 \mathrm{~g} / \mathrm{cm}^{2} /$ year. Peak

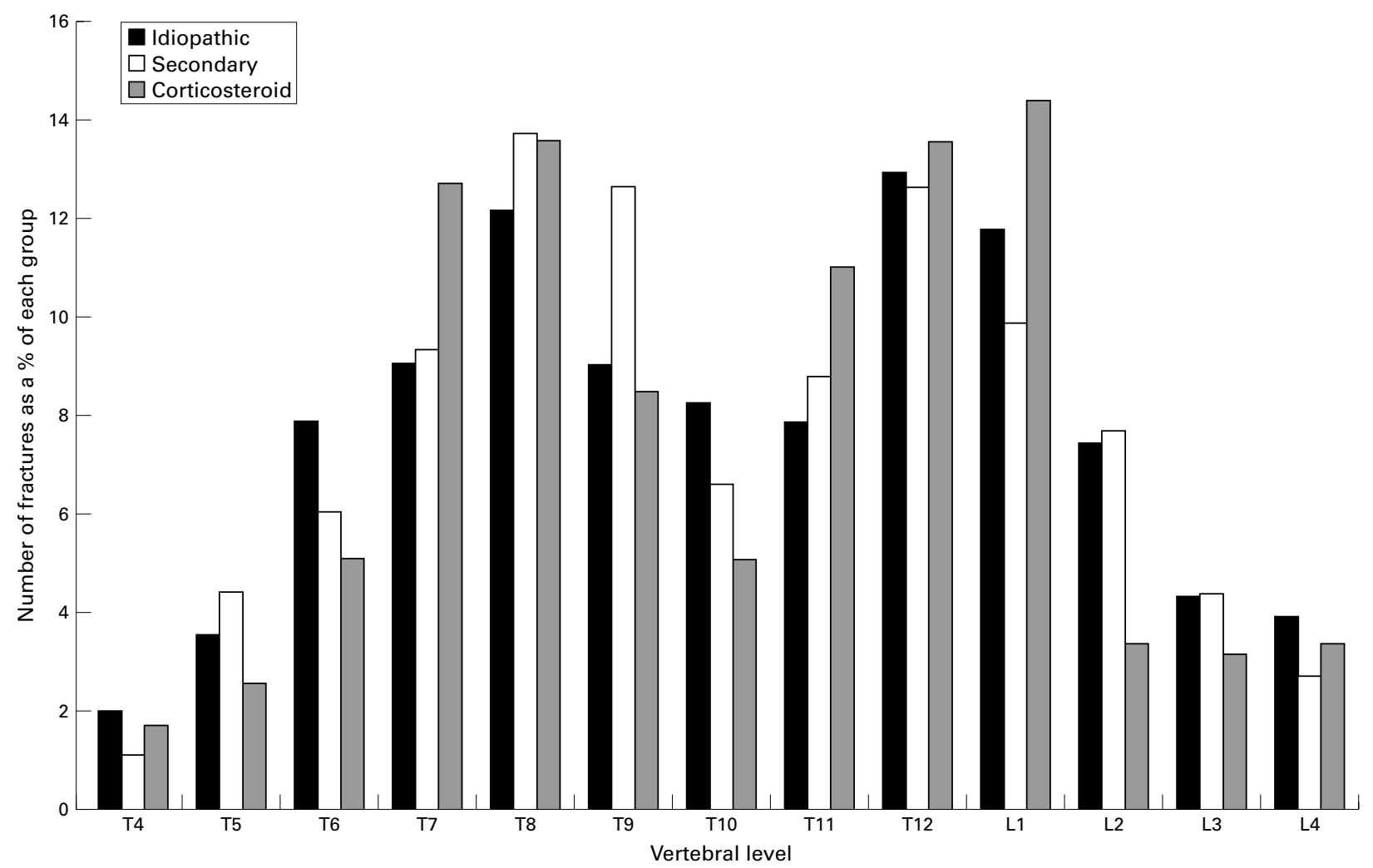

Figure 2 Frequency histogram of location of fractures (as \% of each group) in the three groups of osteoporotic men. 
BMD at the femoral neck occurred at 20-29 years $\left(0.96(0.13) \mathrm{g} / \mathrm{cm}^{2}\right)$ (table 2$)$.

To compare BMD in osteoporotic and control subjects, patients with osteoporosis were matched for age with a control patient. It was possible to match each patient with a control for age in group 2 (mean difference 0.6 years; range 0.02-2.6) and group 3 (mean difference 0.7 years; range $0.01-2.8$ ). In patients in group 1 (idiopathic) only 92 patients could be paired for age (mean difference 0.78 years; range $0.003-4.6$ ). Table 4 gives the results. The data show that height, LS-BMD and FN-BMD were significantly lower in the three groups of patients with osteoporosis and that weight was significantly lower in groups 2 and 3. Groups 1 and 2 showed no change of LS-BMD with age, but FN-BMD declined with age in group 1 $\left(0.0014 \mathrm{~g} / \mathrm{cm}^{2} /\right.$ year $)(\mathrm{p}<0.05)$ and group 2 $\left(0.0044 \mathrm{~g} / \mathrm{cm}^{2} /\right.$ year $)(\mathrm{p}<0.01)$. In group 3 there were no age related changes at either lumbar spine or femoral neck. $\mathrm{T}$ score at the lumbar spine was similar across the groups and averaged -2.44 (1.10). At the femoral neck the $\mathrm{T}$ score was again similar averaging -2.24 (0.85), but was significantly more positive than the $\mathrm{T}$ score at the lumbar spine in men with idiopathic osteoporosis who had up to three fractures $(p<0.01)$. Femoral neck $Z$ scores in patients in group 1 with up to three vertebral fractures $(-1.18(1.09))$ were also more positive than lumbar spine $Z$ scores $(-1.64$ $(0.92) ; p<0.01) . Z$ scores at the spine and femoral neck were not significantly different from each other within groups 2 and 3.

Vertebral deformity was most frequently found at T8 and at T12-L1 (fig 2). All groups showed the same peaks in the spine. The effect of fracture involving L2 on LS-BMD in patients with idiopathic osteoporosis was examined by comparing BMD in patients with a fracture at L2 with patients having no fracture at L2. No significant difference was found (with a fracture at L2: 0.809 (0.16), with no fracture at L2: $0.78(0.13)$ ). Similar findings were detected at L3 and L4 but fewer vertebrae were involved at these levels.

Possible relations between exposure to prednisolone (either daily or lifetime) and either fractures or BMD were investigated but no associations were found.

\section{Discussion}

The advent of population studies of osteoporosis in men such as the EVOS study, ${ }^{13}{ }^{312}$ means that data being collected on asymptomatic subjects may be construed as referring to patients with clinical vertebral fracture. This may not be the case. In the EVOS study men were selected at random from the community and osteoporosis was defined by vertebral deformity without any requirement of pain. In contrast our patients were referred with symptoms, existence of which may be related to low BMD. Similarities do exist between the EVOS approach and the clinical approach. Both EVOS $^{13}$ and the present data yielded subjects who were shorter and lighter than the respective control groups. An important contrast however lies in the difference in bone density between the deformity and osteoporotic groups. In the EVOS study the BMD at the lumbar spine and femoral neck was not low, ${ }^{12}$ whereas the patients with clinical fractures had significantly low BMD at the lumbar spine and femoral neck. Whether vertebral deformity and normal BMD are the precursors of clinical osteoporosis remains uncertain. The relatively young age of men with clinical osteoporosis suggests that deformity would be picked up even younger if there were a progression. Alternatively these patients may have had low BMD throughout life. The constancy of T score with age gives some support to this concept, but patients with low bone density will need to be identified at an early age and followed up longitudinally to establish this point. Care needs to be taken with BMD measurements in older patients because of osteophytes, ${ }^{14}$ which are a possible reason for lumbar spine BMD not falling with age. Deformity and pain may not be related, ${ }^{13}$ but if further studies also suggest that low BMD relates to pain, this would have diagnostic and therapeutic value. The poor relation between deformity and pain may also be the reason for the finding of multiple fractures at initial presentation. As many patients presented with pain it might have been expected that one fracture would have been the most frequent number at presentation, but in all osteoporotic groups a mean of more than two fractures was found at presentation. Duration of pain was not associated with fracture number in any of the groups. Most patients had had pain for 12 months or less, with a trend for corticosteroid treated patients having an even shorter history of back pain. Identification of osteoporosis was most frequently made by the primary care physician by means of radiographs following back pain. Other causes of referral were uncommon. Clustering of vertebral fractures, for which there is little evidence, ${ }^{15}$ - unless the patient is hospitalised $^{16}$ - might be one interpretation for the frequency of multiple fractures at presentation: alternatively initial fractures may not be painful, ${ }^{4}$ or pain attributable to fractures may not be recognised as such leading to late referral of the patients. Nevertheless the frequency of multiple (vertebral) fractures at presentation concurs with the observation of Adinoff and Hollister ${ }^{17}$ who reported that patients (of both sexes) with corticosteroid associated osteoporosis averaged 4.1 fractures (any site) in a retrospective study. The data suggest that the occurrence of a fracture is a serious risk factor for early recurrence in men, whether taking corticosteroids or not. Our data also confirm that symptomatic vertebral fracture is a condition of relatively young men, although our patients with idiopathic osteoporosis were older than in previously reported series, ${ }^{678}$ but slightly younger than the median age reported by Francis et al. ${ }^{18}$ It is possible that there is a predisposition to osteoporosis in men in the latter part of the sixth decade of life that is self limiting, thus giving rise to the steady prevalence seen up to the age of 75 in the EVOS study. ${ }^{1}$ The present data offer no explanation for the cause of such a phenomenon but, it is 
clear that early radiography in men over 50 with back pain may be more important than heretofore acknowledged to establish the diagnosis.

Vertebral fracture number did not show any relation with spinal $\mathrm{Z}$ score whereas a significant downward trend of $\mathrm{Z}$ score was found in the femoral neck in men with idiopathic osteoporosis. These men also had a lower Z score and $\mathrm{T}$ score in the spine compared with the femoral neck. Previous studies suggested that lumbar spine $\mathrm{Z}$ score was lower than $\mathrm{Z}$ scores at other sites in osteoporosis in men. ${ }^{19}$ Our data further indicate that lower $\mathrm{Z}$ scores at the spine are only found in men with idiopathic osteoporosis, and then only in those with up to three vertebral fractures. Together with the observation that femoral neck $\mathrm{Z}$ score in patients with secondary osteoporosis is lower than in idiopathic osteoporosis, this suggests that the spine (largely trabecular bone) is affected preferentially in idiopathic cases, with femoral neck (largely cortical bone) bone being lost less rapidly in the initial stages. Nevertheless increasing cortical bone loss (as shown by FN BMD) is evidently an associate of spine fracture number and progressive loss of cortical bone might be important in determining whether further fracturing occurs. The present findings do however concur with other data suggesting that, as in women, ${ }^{20}$ an average $\mathrm{T}$ score of -2.5 at spine or femoral neck is associated not only with idiopathic osteoporosis in men ${ }^{19}{ }^{21}$ but additionally with secondary and corticosteroid osteoporosis. Deformities or fractures at L2-4 might affect $\mathrm{BMD}^{14}$ and confound relations between BMD and fractures. As no difference was found between BMD in those with fracture at L2, 3, 4 and those without, fracture does not seem to influence interpretation of lumbar spine BMD. In deciding on a value of $\geqslant 20 \%$ deformity as a criterion of fracture, we have followed the method of Scane et $a{ }^{4}{ }^{4}$ Other authors have also suggested a reduction of $15 \%$ to $20 \%$ of posterior:anterior or mid-height, ${ }^{22}$ and in a recent review of male osteoporosis, ${ }^{2}$ a $15 \%$ or $20 \%$ reduction in anterior, posterior or central height is stated as being a commonly accepted radiological definition of fracture. Khosla et $a^{23}$ and Francis et $a l^{18}$ did not define radiological criteria for a fracture, whereas Kelepouris et $a l^{6}$ used a method $^{24}$ that is not ideal because normality is defined by reference to a population of sex hormone deficient women. An alternative method, defining vertebral deformity in terms of number of SDs from normal in individual vertebral dimensions ${ }^{25}$ is too cumbersome for clinical use and data by vertebral level that varies in European countries are not available for England and Wales. Exact comparison between the studies is difficult because of these differing criteria used for diagnosis of fracture. There were clearly two peaks of fracture site, unrelated to the aetiology of osteoporosis. A similar pattern of peaks and nadirs has been reported but differences do exist. ${ }^{26-28}$ Cooper $e t$ $a l^{26}$ reported on a mixed sex population of referred osteoporotic patients including neoplastic causes and found similar peaks at $\mathrm{T} 8$ and L1 with a ratio of 0.82 (T8:L1). In a population study of thoracic vertebrae only in men, Harma et $a l^{27}$ found peaks at T8 and T12 with a ratio of 1.54 , although exact criteria for a fracture were not given. A population study of vertebral deformity in both sexes (men $=69.3$ years, women $=69.6$ years) reported a single peak at T8 or T9 (according to criteria used) with twice as many fractures at T8 as at T12. ${ }^{29}$ However, in a study of aging in men over 85, peaks at $\mathrm{T} 8$ and $\mathrm{T} 12$ were found with almost three times as many fractures at $\mathrm{Tl} 2$ as at $\mathrm{T} 8 .^{28}$ In this study the criterion for diagnosis was an anterior/posterior ratio of 0.66 or less. ${ }^{28}$ While advancing age may predispose to fracture at T12, severity of the disease may also be important. Thus in the mixed population study with no symptoms required, T8 deformity was twice as common as $\mathrm{T} 12^{29}$ : in our study in which symptoms were an entry criteria the ratio was 1:1 with similar values whether idiopathic, secondary or corticosteroid associated: and in men with severe back pain and osteoporosis T12 and L1 were the main sites affected. ${ }^{7}$ Our data also suggest that the cause of osteoporosis is not a factor in determining the site affected. Initial deformity at T8 may occur early but deformity at $\mathrm{T} 12$ suggests more significant disease.

We were not able to confirm, in a male population, the observation that subjects with corticosteroid osteoporosis have a higher mean value of BMD than do patients with noncorticosteroid associated osteoporosis. ${ }^{9}$ However, about $83 \%$ (mean (+1SD)) of men presenting with corticosteroid osteoporosis had a lumbar BMD value of $0.92 \mathrm{mg} / \mathrm{cm}^{2}$ (table 4), which is just above the value (mean $(-1 \mathrm{SD})$ ) of the healthy population of patients aged 60-69 (table 2). Similar arguments apply to idiopathic osteoporosis but screening BMD in men starting to take corticosteroids after age 50 may be valuable in identifying those with low BMD who would benefit from prophylaxis against vertebral fracture. We were also unable to confirm that cumulative dose of corticosteroid is important. ${ }^{30}$ Lifetime dose is difficult to calculate and we had limited numbers and reviewed only patients with a fracture. Nevertheless the high median prednisolone dose concurs with the high incidence of vertebral fractures when cumulative dose exceeds $30 \mathrm{~g}^{31}$

In conclusion we have found that patients with symptomatology and vertebral fracture have low bone density, unlike patients with vertebral deformity alone. Patients present in middle age usually with more than one vertebral deformity suggesting that radiographs should be undertaken earlier after back pain. A BMD T score of -2.50 is appropriate for men for the diagnosis of osteoporosis, including corticosteroid associated osteoporosis. T8 and T12 vertebra are the most frequently affected and involvement of T12 may be associated with more advanced age or more severe disease

Funding: this work was undertaken by the Robert Jones and Agnes Hunt Orthopaedic and District Hospital NHS Trust who received a proportion of its funding from the NHS executive. 
1 O'Neill TW, Felsenberg D, Varlow J, Cooper C, Kanis JA, Silman AJ. The European Vertebral Osteoporosis Study Group. The prevalence of vertebral deformity in European men and women: The European vertebral osteoporosis study. J Bone Miner Res 1996;11:1010-18

2 Eastell R, Boyle IT, Compston J, Cooper C, Fogelman I, Francis RM, et al. Management of male osteoporosis: report of the UK consensus group. Q J Med 1998;91:7192.

3 Burger H, Van Daele PLA, Grashuis K, Hofman A, Grobbee DE, Schutte HE, et al. Vertebral deformities and functional impairment in men and women. J Bone Miner Res 1997;12:152-7.

4 Scane AC, Sutcliffe AM, Francis RM. The sequelae of vertebral crush fractures in men. Osteoporos Int 1994;4:8992.

5 Francis RM, Scane AC, Johnson FJ, Davison CE Sutcliffe AM. Male osteoporosis. In: Ring EFJ, Elvins DM, Bhalla AK, eds. Current research in osteoporosis and bone mineral measurement. London: British Institute of Radiology, 1992: 55 .

6 Kelepouris N, Harper KD, Gannon F, Kaplan FS, Haddad JG. Severe osteoporosis in men. Ann Intern Med $1995 ; 123: 452-60$.

7 Peris P, Guanabens N, Monegal A, Suris X, Alvarez L, Martinez de Osaba MJ, et al. Aetiology and presenting symptoms in male osteoporosis. Br J Rheumatol 1995;34: 936-41.

8 Jackson JA, Kleerekoper M, Parfitt AM, Rao DS, Villanueva AR, Frame B. Bone histomorphometry in hypogonadal and eugonadal men with spinal osteoporosis. J Clin Endocrinol Metab 1987;65:53-8.

9 Luengo M, Picado C, Del Rio L, Guanabens N, Montserrat JM, Setoain J. Vertebral fractures in steroid dependent asthma and involutional osteoporosis: a comparative study. Thorax 1991;46:803-6.

10 Haddaway MJ, Davie MWJ, McCall IW. Bone mineral density in healthy normal women and reproducibility of meassity in healthy normal women and reproducibility of meas-
urements in spine and hip using dual energy X-ray absorpurements in spine and hip using dual en
tiometry. Br J Radiol 1992;65:213-17.

11 Armitage P, Berry G. Statistical methods in medical research. Oxford: Blackwell Scientific Publications, 1987.

12 Stewart A, Felsenberg D, Kalidis L, Reid DM. Vertebral fractures in men and women: how discriminative are bone mass measurements? Br J Radiol 1995;68:614-20.

13 Johnell O, O’Neill T, Felsenberg D, Kanis J, Cooper C, Silman AJ. Anthropometric measurements and vertebral deformities. European vertebral osteoporosis study (EVOS) group. Am J Epidemiol 1997;146:287-93 14 Ito $M$, Hayashi $K$, Yamada $M$, Uetani $M$, Nakamura $T$. spinal fractures in men. Radiology 1993;189:497-502

15 Kanis JA. Treatment of osteoporotic fracture. Lancet 1984; i:27-33.
16 Johnell O, Oden A, Kanis J, Cauline F. Increased risk of further fractures after hospitalization for vertebral fractures, a population based prospective study. Bone 1998;23 (suppl): S152.

17 Adinoff AD, Hollister JR. Steroid-induced fractures and bone loss in patients with asthma. N Engl J Med 1983;309: 265-8.

18 Francis RM, Peacock M, Marshall DH, Horsman A, Aaron JE. Spinal osteoporosis in men. Bone Miner 1989;5:34757 .

19 Vega E, Ghiringelli G, Mautalen C, Rey Valzacchi G, Scaglia $\mathrm{H}$, Zylbertsein $\mathrm{C}$. Bone mineral density and bone size in men with primary osteoporosis and vertebral fractures. Calc Tiss Int 1998;62:465-9.

20 Kanis JA, Melton LJ, Christiansen C, Johnston CC, Khaltaev N. The diagnosis of osteoporosis. J Bone Miner Res 1994:9:1137-41.

21 Melton LJ, Atkinson EJ, O'Connor MK, O'Fallon WM, Riggs BL. Fracture predictions in men versus women. J Bone Miner Res 1997;12 (suppl 1):S543.

22 Lukert M. Vertebral compression fractures: how to manage pain, avoid disability. Geriatrics 1994;49:22-6.

23 Khosla S, Lufkin EG, Hodgson SF, Fiztpatrick LA, Melton III LJ. Epidemiology and clinical features of osteoporosis in young individuals. Bone 1994;5:551-5.

24 Eastell R, Cedel SL, Wahner HW, Riggs BL, Melton III LJ. Classification of vertebral fractures. J Bone Miner Res 1991;6:207-15.

25 O'Neill TW, Varlow J, Felsenberg D, Silman AJ. Variation in vertebral height ratios in population studies. J Bone Miner Res 1994;9:1895-907.

26 Cooper C, Atkinson EJ, O'Fallon M, Melton W. Incidence of clinically diagnosed vertebral fractures: a populationbased study in Rochester, Minnesota 1985-1989. J Bone Miner Res 1992;7:221-7.

27 Harma M, Heliovaara M, Aromaa A, Knekt P. Thoracic spine compress

C, Mellstrom D, Rosengren $K$, Rundgren $A$. Prevalence of vertebral fractures in 85-year-olds. RadioPrevalence of vertebral fractures in 85 -year-olds. Radiographic examinat

29 Jones G, White C, Nguyen T, Sambrook PN, Kelly PJ, Eisman JA. Prevalent vertebral deformities: relationship to bone mineral density and spinal osteophytosis in elderly men and women. Osteoporos Int 1996;6:233-9.

30 Lukert BP, Johnson BE, Robinson RG. Estrogen and progesterone replacement therapy reduces gluco-corticoid induced bone loss. J Bone Miner Res 1992;7:1063-9.

31 Dykman TR, Gluck OS, Murphy WA, Hahn TJ, Hahn BH. Evaluation of factors associated with glucocorticoidinduced osteopoenia in patients with rheumatic diseases. Arthritis Rheum 1985;28:361-8. 